\title{
メカニカルアロイング法による $\mathrm{Nb}_{3} \mathrm{Al}$ 複合材の作製
}

\author{
兼吉 高宏湤 1 , 高橋 輝男江 1 \\ 林行信放, 元山 宗之的
}

蚆 兵庫県立工業技術センター， テ654 神戸市須磨区行平町3-1-12.

们2 兵庫県立工業技術センター機械金属工業指導所， $\overline{\mathbf{T}} 673-04$ 三木市平田240-1.

\section{Preparation of $\mathbf{N b}_{3} \mathrm{Al}$ Composite by Mechanical Alloying}

\author{
Takahiro Kaneyoshi ${ }^{\text {‘ } 1}$, Teruo Takahashi ${ }^{\text {ţ } 1}$ \\ Yukinobu Hayashi ${ }^{\text {触 }}$ and Muneyuki Motoyama
}

\footnotetext{
Hit Hyogo Prefectural Institute of Industrial Research, 3-1-12 Yukihira-cho Suma-ku, Kobe 654.

t22 Technical Center for Machinery and Metals, Hyogo Prefectural Institute of Industrial Research, 240-1 Hirata, 673-04.
}

Received July 14, 1994

\begin{abstract}
$\mathrm{Nb}, \mathrm{Al}, \mathrm{Ti}, \mathrm{C}$ and $\mathrm{B}$ powders were mechanically alloyed(MA) in an Ar gas atmosphere. The results of $\mathrm{X}$-ray diffraction indicated that for the starting composition of $\mathrm{Nb}_{3} \mathrm{Al}, \mathrm{Nb}$ solid solution was obtained in the early stage of MA process, thereafter it became to be amorphous. $\mathrm{Nb}_{3} \mathrm{Al}$ compound was obtained by vacuum heating of $72.0 \mathrm{ks} \mathrm{MA}$ powders. $\mathrm{Nb}_{3} \mathrm{Al}$ and $\mathrm{TiC}$ were obtained in the system of the composition of $\mathrm{Nb}_{3} \mathrm{Al}-30 \mathrm{vol} \% \mathrm{TiC}$ by vacuum heating of $72.0 \mathrm{ks}$ MA powders. Furthermore, fine $\mathrm{TiC}$ particle dispersed $\mathrm{Nb}_{3} \mathrm{Al}$ composite was obtained by HIP processing of MA powders. TEM observation of the HIPed compacts revealed that $\mathrm{TiC}$, which was more less than $0.1 \mu \mathrm{m}$, precipitated on fine grained $\mathrm{Nb}_{3} \mathrm{Al}$ matrix.
\end{abstract}

\section{1 緒 言}

超音速旅客機やスペースプレーンなどに使われる材 料として，高温でも優れた機械的特性を維持するいわ ゆる次世代の耐熱材料として，金属間化合物が期待さ れ，研究，開発が進んでいる。このような材料は一般 に常温延性に之しく加工性が墨いため，常温延性の改 善を行う，あるいは粉末治金法を利用して材料作製後 の加工が少ないニアネットシェイプ材を作製するなど の方策がとられている，またより高温特性に優れた 材料亡して，金属間化合物にセラミックス繊維あるい は粒子を分散させた複合材料が考えられる。このよう な材料には溶解法での作製，延性の付与などは非常に
困難であり，粉末治金法を用いるのが最も一般的であ ると考えられる。

一方，メカニカルアロイング（MA）法を用いた各 種セラミックスと合金粉末を用いたセラミックス分散 合金，素粉末同士の反応を利用した複合材料の作製な ど多くの研究が行われている1-5)。

著者らはこれまで，高温での機械的特性に優れた $\mathrm{Al}-\mathrm{Nb}$ 系金属間化合物のうち，軽量性，耐酸化性に有 利な $\mathrm{Al}_{3} \mathrm{Nb}$ にいて，素粉末を出発材料として粉末治 金法とMA法を組み合わせた $\mathrm{Al}_{3} \mathrm{Nb}$ 複合材料の作製に ついて榆討を行ってきた ${ }^{6-7}$ 。 その中で $\mathrm{Al}_{3} \mathrm{Nb}$ 組成の MA処理ではasMA状態でAlと $\mathrm{Nbが反心し，} \mathrm{Al}_{3} \mathrm{Nb}$ が生 
成する. また, MA過程で粉末が容器へ付着するのを 防止するために, メ夕ノールなどのアルコールを添加 してMA処理を行った場合, Nbとアルコール中のCが 反応してNb炭化物が生成することが明らかにしてい る.

本研究では同様の $\mathrm{Al}-\mathrm{Nb}$ 系金属間化合物であり,

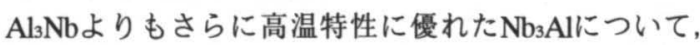
MA処理における基礎的な反応を調べるとともに $\mathrm{Nb}_{3} \mathrm{Al}$ をマトリックスとし, セラミックスを分散させ た複合材料の作製について検討を行った.

\section{2 実験方法}

出発材料として市販の純 $\mathrm{Nb}$ ( $99.5 \mathrm{mass} \%$, 以後\%と 略す），純 $\mathrm{Al} （ 99.99 \% ） ，$ 純 $\mathrm{Ti} （ 99.0 \% ） ，$ 純 B （99.0\%）およびグラファイト粉末を用いた。これら の粉末を $\mathrm{Nb}_{3} \mathrm{Al}$ あるいは $\mathrm{Nb}_{3} \mathrm{All}$ に30vol\%の NbC， NbBあ るいは $\mathrm{TiC}, \mathrm{TiB}, \mathrm{TiB}_{2}$ が生成する組成に配合し， $\mathrm{MA}$ 処理を行った. MA処理には粉砕/混合ミル（Spex Co., Spex8000）を用い, Ar雾囲気中で最長 $360.0 \mathrm{ks}$ で行った. また, 容器とボールの材質はそれぞれ SUS304およびSUJ2であり，ボールと配合粉末との重 量比は3対1である. $\mathrm{Al}$ と Nb粉末のみのMA処理では容 器の壁に付着する粉末量が多く, MA粉末の回収量が 非常に少なかったため, メ夕ノールを約5cc添加して MA処理した実験も行った.

得られたMA粉末についてX 線回折 $(\mathrm{CuK} \alpha)$ によ る相の同定および走查型電子顕微鏡（SEM）観察を 行った. また, 粉末を樹脂に埋め込み, 断面組織の観 察を行った. MA粉末の一部は圧粉成形後, $1273 \mathrm{~K} の$ 温度で3.6ks真空熱処理を行った，あるいはSUS304製 のカプセルに真空封入後, 1273および1473Kの温度で, 圧力 $196 \mathrm{MPa} ， 3.6 \mathrm{ks}$ の熱間等方圧加圧（HIP）処理を 行った. 熱処理材およびHIP処理材はX $\mathrm{X}$ 線回折測定, SEM, 透過電子顕微鏡（TEM）観察およびマイクロ ビッカース硬度計による硬さ測定を行った。

\section{3 実験結果および考察}

$\mathrm{Nb}_{3} \mathrm{Al}$ の組成に配合し, 各時間 $\mathrm{MA}$ 処理を行った粉 末の X 線回折図形をFig.1に示す. 3.6ksの MA初期から すでにAlの回折ピークは見られなくなり， Nbピーク のみが認められる.これはMA処理により NbにAlが固 溶し，Nbの強制固溶体になったものと考えられる. さらに, MA処理が進むにつれてNbピークはブロード 化し，360.0ksではほとんどピークらしきものは認め

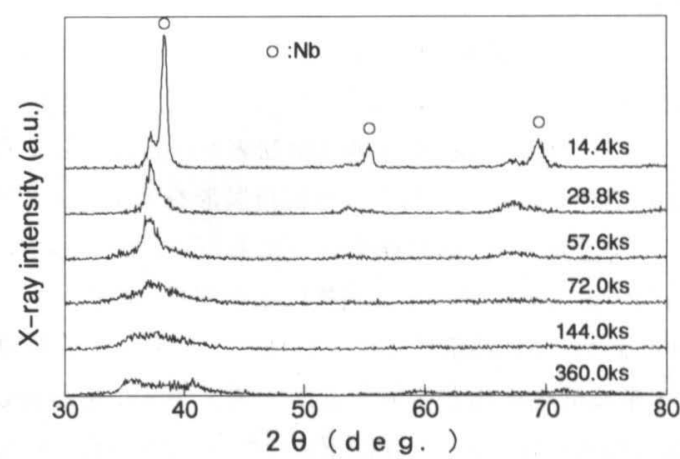

Fig. $1 \mathrm{X}$-ray diffraction patterns of $\mathrm{Nb}_{3} \mathrm{Al}$ powders mechanicaly alloyed for various times.

られなくなる. $\mathrm{Al}_{3} \mathrm{Nb}$ 組成の場合は $\mathrm{MA}$ 処理が進むに つれて $\mathrm{Al}$ とbが反応し, $\mathrm{Al}_{3} \mathrm{Nb}$ 金属間化合物が生成す るが ${ }^{6)}$, 本研究で行った $\mathrm{Nb}_{3} \mathrm{Al}$ 組成では反応生成物は 認められず, Nb固溶体になった後, 最終的にアモル ファスが形成されることがわかった。

Photo.1に Nb3 Al組成で各時間MA処理を行った粉末 の外観および断面組織を示す. MA初期には粒子径む 大きく, 扁平状をしているが, MA処理が進むにつれ て粒子径が小さくなり形状も球状になってくる，また
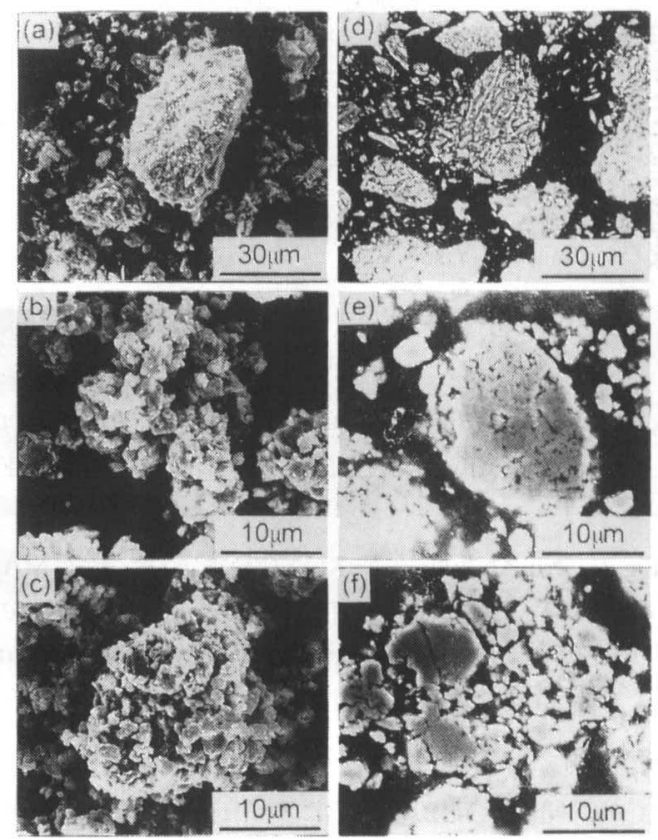

Photo.1 SEM micrographs of $\mathrm{Nb}_{3} \mathrm{Al}$ powders mechanicaly alloyed for various times.

(a)(b)(c) Shapes of the powder particles.

(d)(e)(f) Micrographs of the sectioned particles.

(a)(d) $14.4 \mathrm{ks}$, (b)(e) $43.2 \mathrm{ks}$, (c)(f) $72.0 \mathrm{ks}$ 
断面組織から，MA初期にはNb，Alのラメラ組織を示 しているが，MA処理が進むにつれて均質な組織にな るのがわかる.

Fig.2に $\mathrm{Nb}_{3} \mathrm{Al}$ 組成の $72.0 \mathrm{ksMA}$ 粉末を圧粉成形し，真 空熱処理を行った試料のX線回折図形を示す.メ夕ノ 一ルを添加してMA処理を行ったものと，添加しない もので熱処理後の反応生成物に相違が見られた.

すなわち， $\mathrm{Nb}_{3} \mathrm{Al}$ 組成では熱処理により配合組成の $\mathrm{Nb}$ 3Al金属間化合物が生成したが, メ夕ノールを添加し たものでは $\mathrm{Nb}_{3} \mathrm{Al}$ の生成は認められす， Nbの炭化物で ある $\mathrm{Nb}_{2} \mathrm{C}$ とbの生成が認められた。なお，メタノー ル添加と無添加ではasMAの状態では同様のX線回折 図形を示している。このような結果になったのは,メ タノール中のCと $\mathrm{Nb}$ 仮応し $\mathrm{Nb}_{2} \mathrm{C}$ 珄成し, 租成の ずれにより $\mathrm{A} 1$ の固溶したNbが残ったためと考えられ た. 前述のようにメタノールと $\mathrm{Nb} 反$ 応については, $\mathrm{Al}_{3} \mathrm{Nb}$ 組成の $\mathrm{MA}^{6)}$ あるいは $\mathrm{Nb}$ 粉末のアルコール中で のグラインディング あるいはTiなどの他の元素と炭 化水素とのグラインディング9) の研究でも認められて いる.

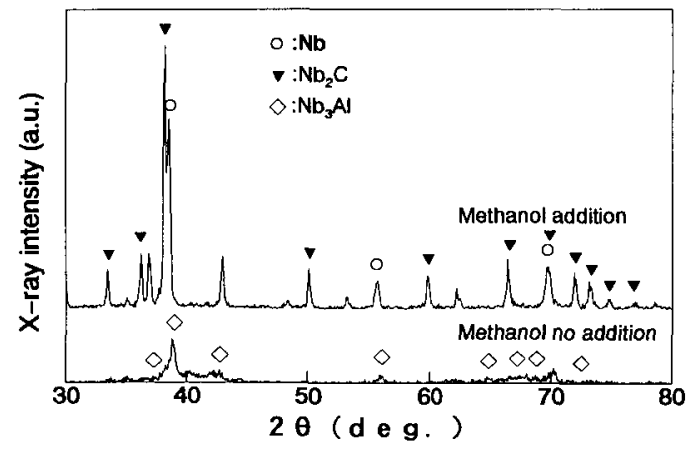

Fig.2 $\mathrm{X}$-ray diffraction patterns of $\mathrm{Nb}_{3} \mathrm{Al}$ powders mechanically alloyed for $72.0 \mathrm{ks}$, heated at $1273 \mathrm{~K}$.

Fig.3に Nb3 Al-30vol\% NbX(X=C,B $\left.{ }_{2}\right)$ の組 成で MA, 熱処理を行った試料のX線回折図形を示す．いずれの 組成についても $\mathrm{Nb}_{3} \mathrm{Al}$ の生成は認められず， Nbの炭化 物およびホウ化物と $\mathrm{Nb}$ 生成が認められた。生成し た炭化物，ホウ化物はそれぞれ $\mathrm{Nb}_{3} \mathrm{Al}-\mathrm{NbC}$ 組成で $\mathrm{Nb}_{2} \mathrm{C}$ が， $\mathrm{Nb}_{3} \mathrm{Al}-\mathrm{NbB}_{2}$ 組成では $\mathrm{Nb}_{3} \mathrm{~B}_{2}$ であった.いずれ も配合組成よりも高 $\mathrm{Nb}$ 組成の炭化物，ホウ化物であ り，これらの生成にNbが消費され，Nb3Alから低Nb側 に組成がずれるため $\mathrm{Nb}_{3} \mathrm{Al}$ の生成が認められなかった もの之考えられる。

以上のように, $\mathrm{Nb}_{3} \mathrm{Al}-\mathrm{NbX}$ 組成では $\mathrm{Nb}_{3} \mathrm{Al}$ 複合材を

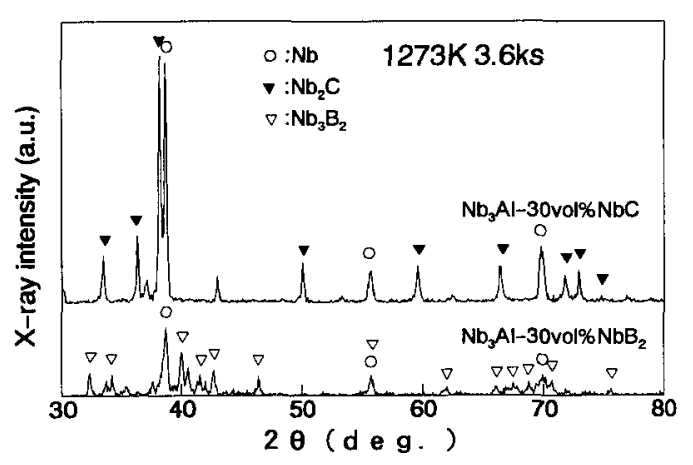

Fig.3 X-ray diffraction patterns of $\mathrm{Nb} 3 \mathrm{Al}-30 \mathrm{vol} \% \mathrm{NBX}$ powders mechanically alloyed for $72.0 \mathrm{ks}$, heated at $1273 \mathrm{~K}$.

得ることが出来なかったここれはNbの炭化物および ホウ化物の生成エンタルピーがNb3Alに比へて大きく， $\mathrm{Nb}$ の炭化物，木ウ化物の生成が優先的に起こったこ とが主な原因であると考えられる。したがって，Nb あるいはAlよりもC，Bと反応しやすい元素を添加し， その元素の炭化物，ホウ化物を優先的に生成させれば $\mathrm{Nb}$ とAlとの反応が組成通りに起こり， Nb3 Alが生成す ると考えられる。

そこでNbとAlよりもC，Bと反応しやすい元素とし てTiを選択し， Nb3 Al-30vol\%TiX（X=C,B,B2）の組成 に配合し，72.0ksMA，熱処理を行った. Fig.4に熱処 理材のX楾回折図形を示す. $\mathrm{Nb}_{3} \mathrm{Al}-\mathrm{TiB}, \mathrm{TiB} 2$ 組成で はNb3 Alの生成が認められなかったが， Nb3 Al-TiC組 成では TiCおよび $\mathrm{Nb}_{3} \mathrm{Al}$ の生成が認められ， TiCと $\mathrm{Nb}_{3} \mathrm{Al}$ の複合粉末が得られることがわかった。

さらに, Nb3Al-TiC組成の 72.0ksMA粉末をHIP処理 により固化成形を行った。 $1473 \mathrm{~K} の H I P$ 処理材の断面 組織をPhoto.2に示す. $0.1 \mu \mathrm{m}$ 前後の非常に微細な粒

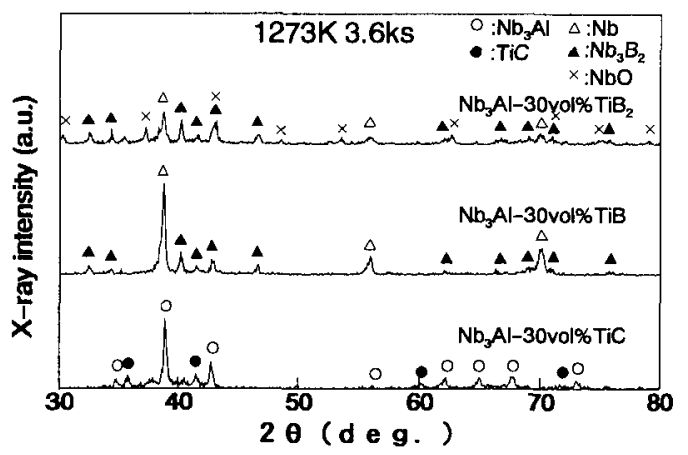

Fig.4 X-ray diffraction patterns of Nb3Al-30vol\%TiX powders mechanically alloyed for $72.0 \mathrm{ks}$, heated at $1273 \mathrm{~K}$. 


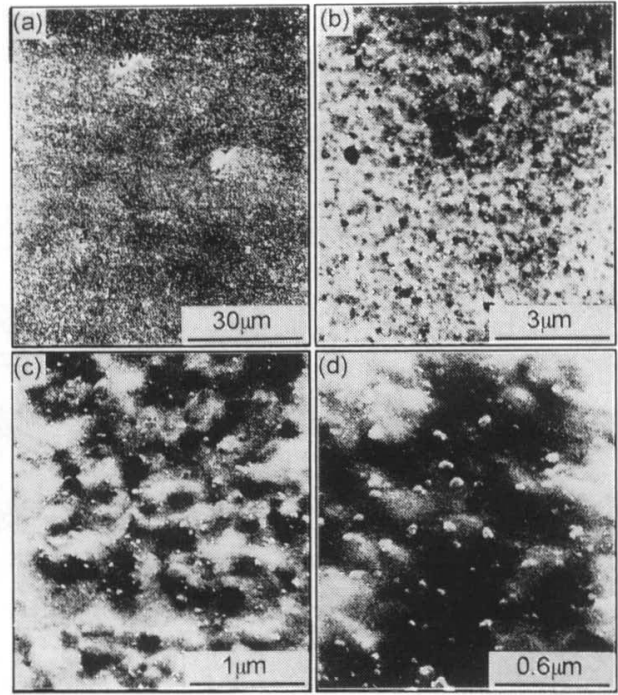

Photo.2 SEM microographs of the HIPed compact of $\mathrm{Nb}_{3} \mathrm{Al}-30 \mathrm{vol} \% \mathrm{TiC}$ mechanicaly alloyed for $72.0 \mathrm{ks}$.

子がほぼ均一に分散しているのが認められた。これら の粒子はEDX分析およびX 線回折の結果からTiCであ ることがわかった

Photo.3に1273KでHIP処理を行った試料のTEM像を 示す. $1473 \mathrm{~K} の H I P$ 処理材よりもさらに微細な数十 $\mathrm{nm}$ 程度のTiCが認められる.さらに，マトリックスであ る $\mathrm{Nb}_{3} \mathrm{Al}$ の結晶粒径約も $0.1 \mu \mathrm{m}$ の非常に微細なもので あることがわかる．また， $\mathrm{Nb}_{3} \mathrm{Al}$ 単相の硬さが $\mathrm{Hv} 800$ 程度なのに対して, HIP処理材の硬さはHv1000程度ま で上昇し, TiCの分散効果が認められた。 なお, 得ら れたHIP処理材にはポアがまだかなり認められ，固化 成形についてはさらに検討する必要があると思われた.

以上のように，MAおよびその後の熱処理を用いる ことにより, 非常に微細なTiC粒子が均一微細に分散 した $\mathrm{Nb}_{3} \mathrm{Al}$ 金属間化合物基複合材料を作製できること が明らかになった。
4 まとめ

(1)Nb3Al組成のMAでは, 化合物相は認められず, Nb 固溶体を形成した後，アモルファス化が起こった．

(2)MA粉末を熱処理することにより $\mathrm{Nb}_{3} \mathrm{Al}$ 化合物相が 得られたが, メタノールを添加してMA, 熱処理 した場合, メタノール中のCと $\mathrm{Nb}$ 泎応し、 $\mathrm{Nb}_{2} \mathrm{C}$

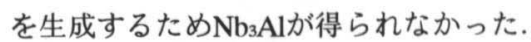

(3) $\mathrm{Nb}_{3} \mathrm{Al}-30 \mathrm{vol} \% \mathrm{NbX}\left(\mathrm{X}=\mathrm{C}, \mathrm{B}_{2}\right)$ 組成のMA, 熱処理に おいても $\mathrm{Nb}_{3} \mathrm{Al}$ 相は認められなかった。これは $\mathrm{Nb}$ とCあるいはBとの反応が優先的に起こり, $\mathrm{Nb}_{3} \mathrm{Al}$ よりも低Nb側へ組成がずれるためと考えられた.

(4)Nb, AlよりもCと反応しやすいTiを加え, $\mathrm{Nb}_{3} \mathrm{Al}-$ 30vol\% TiC組成でMA，熱処理することにより TiC およびNb33 Alの生成が認められた。

(5) Nb 3 Al-TiC組成のMA粉末をHIP処理による固化成形

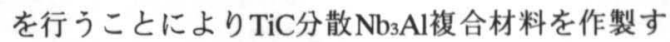
ることができた

文献

1) J.S.Benjamin: Metall. Trans., 1(1970)2943.

2) G.H.Gessinger: Metall. Trans., 7A(1976)1203.

3) J.S.Benjamin and M.J.Bomford: Metall. Trans., 8A(1977)1301.

4) G.Jagg, F.Kunter and G.Korb: Powder Met. Int., 9(1977)24.

5) P.S.Gilman and M.J.Bomford: Metall. Trans., 12A(1981)813.

6)兼吉高宏, 高橋輝男, 林行信, 元山宗之: 粉体お よび粉末冶金, 39(1992)660.

7)兼吉高宏, 高橋輝男, 林行信, 元山宗之 : 粉体お よび粉末冶金, 41(1994)166.

8) T.Kaneyoshi, T.Takahashi and M.Motoyama: Scripta Metall. Mater., 29(1993)1547.

9) K.Tokumitsu: Mat. Sci. Forum, 8(1992)715.
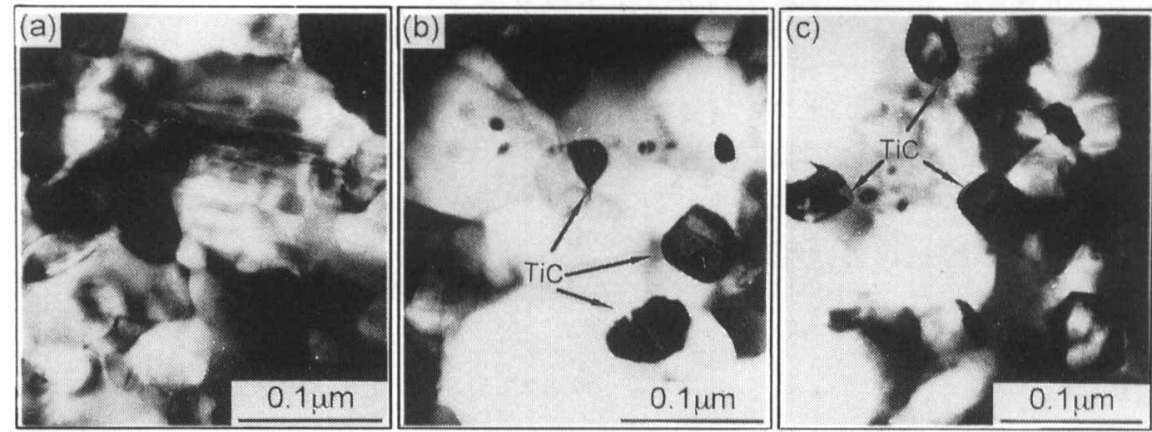

Photo.3 TEM images of the HIPed compact of $\mathrm{Nb}_{3} \mathrm{Al}-30 \mathrm{vol} \% \mathrm{TiC}$ mechanicaly alloyed for $72.0 \mathrm{ks}$. 